\title{
Is there a relationship in-between ovarian endometriosis and ovarian cancer? Immunohistochemical profile of four cases with coexisting ovarian endometriosis and cancer
}

\author{
Roxana-Cleopatra Penciu ${ }^{1)}$, IUlia Postolache ${ }^{2)}$, Liliana Steriu ${ }^{1)}$, Silvia IzVoranu ${ }^{1)}$, \\ ANDREI-AdRIAN TICA ${ }^{3)}$, IULIA-Diana MOCANU ${ }^{1)}$, VASILE SÂRBU ${ }^{4)}$, MARIANA DEACU ${ }^{5,6)}$, \\ IRINA TICA ${ }^{7)}$, GABRIELA-IZABELA BĂLTĂTESCU ${ }^{5,8)}$, OANA-SORINA TICA ${ }^{1,9)}$, VLAD-IUSTIN TICA ${ }^{10)}$ \\ 1) Department of Obstetrics and Gynecology, Doctoral School, Ovidius University of Constanta, Romania \\ 2) PhD Student, Doctoral School, Ovidius University of Constanta, Romania \\ 3) Department of Clinical Pharmacology, University of Medicine and Pharmacy of Craiova, Romania \\ 4) Department of Surgery, Doctoral School, Ovidius University of Constanta, Romania \\ ${ }^{5)}$ Clinical Service of Pathology, Sf. Apostol Andrei Emergency County Hospital, Constanta, Romania \\ ${ }^{6)}$ Department of Pathology, Faculty of Medicine, Ovidius University of Constanta, Romania \\ 7) Department of Internal Medicine, University Regional Hospital, Constanţa, Romania; \\ Department of Internal Medicine, Ovidius University of Constanța, Romania \\ ${ }^{8)}$ Center for Research and Development of the Morphological and Genetic Studies of Malignant Pathology, \\ Ovidius University of Constanta, Romania \\ 9) Department of Obstetrics and Gynecology, University Regional Hospital, Craiova, Romania \\ ${ }^{10)}$ Department of Obstetrics and Gynecology, Ovidius University of Constanta, Romania
}

\begin{abstract}
Endometriosis (EMs) is a benign disease characterized by the presence of endometrial tissue outside the uterine cavity. EMs associated with ovarian cancer (OC) has a relative low incidence (5\% to 10\%), sometimes with evidence of a transition stage through atypical EMs (1.6\% cases). We have assessed 135 consecutive patients with either EMs or OC and, out of them, our study reports on four cases of ovarian EMs and OC: two cases with endometrioid OC and two cases with high-grade serous OC (HGSOC). Cases with EMs and HGSOC are extremely rarely reported in the literature - we could find not more than 30 cases. The main objective of our research was to observe the possible similarities between EMs and OC. Secondly, we analyzed the differences between EMs associated with endometrioid OC and EMs associated with HGSOC. We evaluated them in terms of clinical status (age, stages of EMs and OC) and immunohistochemical (IHC) expression of estrogen receptor (ER), progesterone receptor (PR), Ki67, p53, p16, Wilms' tumor 1 (WT1), cluster of differentiation (CD) 34 and CD10 immunomarkers - we could not find in the literature all these markers assessed, in the same time, to such samples. Our results indicated that there are no similarities between EMs and OC and no atypical EMs was identified in our cases. We recorded higher values of ER expression in EMs associated with HGSOC than in EMs associated with endometrioid OC. Higher values of ER expression were also recorded in OC than in endometriotic foci. There were no differences in proliferative rate of endometriotic foci associated with endometrioid OC, compared to EMs associated with HGSOC. An aberrant IHC expression for p53 protein and p16 protein was noted only in HGSOC. Also, a positive immunostaining for Wilms' tumor 1 (WT1) was identified only in HGSOC. Higher values of microvessel density were recorded in OC but not in endometriotic foci. We concluded that there were no similarities between EMs and OC for the cases included in our study, but we noticed differences in terms of Ki67 index and also between hormonal receptors expression in EMs associated with HGSOC, comparing with EMs associated with endometrioid OCs. These results may represent a "brick" for future researches on the less understood EMs associated with type II of OCs, especially with HGSOC. Identifying the best marker, which can predict the risk of developing OC for the patients with EMs, may lead to discover new specific therapeutic agents and, therefore, a better, tailored, therapy.
\end{abstract}

Keywords: endometriosis, endometrioid ovarian cancer, serous ovarian cancer, immunohistochemistry.

\section{Introduction}

Endometriosis (EMs) is a benign disease characterized by the presence of endometrial tissue outside the uterine cavity [1]. In terms of location of the lesions, ovarian endometriomas are the most frequently found, even if there are also other sites involved - like peritoneal, cervical, Caesarean (C)-section scar or rectovaginal space [2]. It is frequently related to pain $[3,4]$. The severity of the disease is most frequently assessed upon American Society of Fertility and Sterility (ASFS) classification (stages of EMs)
[5]. Even if EMs is categorized as a benign lesion, it still carries worrisome clinical and morphological features like the capacity to invade and to destroy the surrounding tissue and it is associated with an increased risk for malignancy in the adjacent region [6]. Malignant lesions associated with endometriotic foci have been frequently reported in the literature, ovary being the most involved one [1]. Heaps et al. (1990) found that from 205 cases with EMs and cancer, the ovary was the primary site in $79 \%$ of the cases [7]. Different authors report a $5 \%$ to $10 \%$ of EMs cases associated with ovarian cancer (OC),

This is an open-access article distributed under the terms of a Creative Commons Attribution-NonCommercial-ShareAlike 4.0 International Public License, which permits unrestricted use, adaptation, distribution and reproduction in any medium, non-commercially, provided the new creations are licensed under identical terms as the original work and the original work is properly cited. 
in some of them with evidence of a transition stage through atypical EMs - in up to $1.6 \%$ of cases (mainly with architectural atypia) $[8,9]$. EMs-associated OCs (EAOCs) are classified in three categories according to Van Gorp et al. (2004): category A consists of OC characterized by contiguity with an ovarian endometriotic focus; category $\mathrm{B}$ includes all $\mathrm{OC}$ without a transition zone but with the same laterality for EMs; category $\mathrm{C}$ is represented by all $\mathrm{OC}$ and other non-ovarian endometriotic foci $[10,11]$. The most frequent morphological subtypes of ovarian tumors associated with EMs are those included in type I category of Kurman's molecular classification of OC [endometrioid, clear cell, mucinous, transitional cell, borderline and low-grade serous carcinoma (LGSC)] [12]. Ovarian tumors included in type II category (high-grade serous carcinoma, undifferentiated carcinoma and malignant mixed mesodermal tumors) are rarely associated with EMs [6].

In the present research, we intended to investigate the relationship between ovarian EMs and concomitant OC in four cases identified (two with endometrioid $\mathrm{OC}$ and the other two with serous OC), through ancillary study. Our main objective is to determine whether there is any association between ovarian EMs and concomitant OC. Our secondary objective consisted in determine if there are differences between EMs associated with different morphological types of OC. For this reason, we immunohistochemically assessed the following immunomarkers: estrogen receptor (ER), progesterone receptor (PR), Ki67, p53, p16, cluster of differentiation (CD) 34 and Wilms' tumor 1 (WT1). In addition, we immunohistochemically assessed the expression of CD10, a well-known immunomarker of normal endometrial stroma [13], to prove the existence of endometrial stroma in endometriotic foci [14].

All of these immunomarkers play a specific role for both EMs and cancer. The impact of hormone receptors (ER, PR) over endometrial-type tissue and ovarian parenchyma has been intensely investigated and it was proved that their expression is important not only in the normal functionality of the endometrium or of the ovary, but also in the processes of EMs and cancer development [15, 16]. Higher levels of hormonal expression are exhibited in ectopic endometrial tissue, comparing with normal endometrium [15] and also in OCs [16]. An imbalance of their expression can lead to a different result and they must always be evaluated taking into consideration the pattern of the immunohistochemical (IHC) staining and hormonal status.

Anti-Ki67 antibody is an important immunomarker which helps to evaluate the cells proliferation rate [13]. The development and growth rate of a neoplastic process and its aggressivity can be evaluated through IHC assessment of the Ki67 labeling index [17].

Disruption of the cellular apoptosis is an important mechanism in promoting and progression towards a malignant lesion. The $\mathrm{p} 53$ protein (a tumor-suppressor factor) and the p16 protein [a cyclin-dependent kinase (CDK) inhibitory protein] have both an extremely important role in controlling cell cycle and their expressions are frequently altered in carcinoma $[18,19]$. In our study, we chose to immunohistochemically investigate their expressions in EMs in order to see if there is a similar biological behavior as in OC. For the same reason, we also decided to study in our cases the IHC expression of WT1 immunomarker, a transcription factor protein which plays an important role in the cell cycle and apoptosis, among other important functions [20]. WT1 is considered to be a tumor-associated antigen as p53 [20] and is frequently express in serous OC $[18,21]$.

Angiogenesis or neovascularization represents an important mechanism not only for developing and growing of a malignant tumor, but also for EMs to invade and to persist in the host tissue. This process is a complex one and is characterized by the growth of new vessels from preexisting ones. It can be evaluated through a semiquantitative method - microvessel density (MVD). In our study, we established MVD by the IHC assessment of CD34 immunomarker, a transmembrane phosphoglycoprotein, which is a pan-endothelial marker for endothelial cells and correlates well with angiogenesis in tissues [13].

Reviewing databases regarding EMs and EAOC, we found no more than 30 cases of serous OC associated with EMs reported [6, 11, 22-24]. More, we did not find any articles studying the expression of all above-mentioned immunomarkers in patients with EMs and/or OC. Our study could bring new insights on the possible associations between clinical, morphological features and molecular changes of EMs and, possibly related, OC.

\section{a Patients, Materials and Methods}

In our retrospective study, we screened all patients surgically treated and pathologically confirmed in the Sf. Apostol Andrei Emergency County Hospital, Constanţa, Romania, with either EMs (ovarian, peritoneal, cervical and C-section scar) between 2015 and 2017 or OC, between 2013 and 2017. From 135 patients with either EMs or with OC, we identified four of them with both concomitant ipsilateral ovarian EMs and OC. These cases were assessed in terms of a panel of clinical-morphological features: age, social status, parity, menopausal status, symptoms at hospital admission, endometrial phase, stage of EMs, morphological type of $\mathrm{OC}$ according to the World Health Organization (WHO) Histological Classification for ovarian tumors [21], grade and stage of OC based on International Federation of Gynecology and Obstetrics (FIGO) criteria [25]. A written informed consent was available from all patients included in our study.

All cases were reevaluated and representative samples were selected for immunohistochemistry. A manual method of IHC staining was performed on $4 \mu \mathrm{m}$-thick sections of formalin-fixed, paraffin-embedded tissue blocks of cases included in the present study. After the epitope retrieval, tissue sections were incubated with the following primary antibodies from Biocare Medical (ready-to-use): antiCD10 (mouse monoclonal, 56C6 clone), anti-ER (rabbit monoclonal, SP1 clone), anti-PR (rabbit monoclonal, SP2 clone), anti-CD34 (mouse monoclonal, QBEnd10 clone), anti-Ki67 (rabbit monoclonal, SP6 clone), anti-p53 (mouse monoclonal, DO-7 clone), anti-p16 ${ }^{\mathrm{INK} 4 \mathrm{a}}$ (mouse monoclonal, G175-405 clone) and anti-WT1 (mouse monoclonal, BC.6F$\mathrm{H} 2$ clone). The protocol of immunostaining provided by the manufacturer was followed for each of them. We used 3,3'-Diaminobenzidine (DAB) as chromogen, with brown staining. Sections were finally counterstained with Mayer's 
Hematoxylin. As a positive tissue control, it was used tonsil for CD10 and CD34, normal breast tissue for ER and PR, colon carcinoma sample for p53, mesothelioma sample for WT1 and normal testis for p16.

\section{IHC assessment}

The presence of endometrial-type of stroma in the EMs was highlighted by a positive membrane immunostaining of stromal cell for CD10 [14]. Expression of hormone receptors was evaluated using $H$-score (a semi-quantitative method), which implies evaluation both of the intensity score (none -0 , weak -1 , moderate -2 , strong -3 ) and percentage of cells stained on nuclear level. The $H$-score formula is $3 \times$ percentage of strongly staining nuclei +2 $\times$ percentage of moderately staining nuclei + percentage of weakly staining nuclei, giving a range of 0 to 300 and the cut-off value is $1 \%(<1 \%$ of cells is considered a negative expression) [26]. IHC assessment of endometriotic foci for hormone receptors was done in both epithelial and stromal cells. A positive IHC reaction for Ki67 was considered when a nuclear brown staining was present. Assessment of the proliferation rate in the endometriotic foci and OCs was done based on Ki67 index and categorized as follows: negative $-<1 \%$; very low $\geq 1 \%-<5 \%$; low $\geq 5 \%-<10 \%$; moderate $\geq 10 \%-<40 \%$; strong $->40 \%$ $[16,27]$. Nuclear expression of p53 protein was evaluated for its intensity and distribution: a normal expression known as "wild type" was considered for weakly and focal brown nuclear staining; an altered expression can be either "null type" (no nuclear staining) or "overexpression type" (strong and moderate nuclear staining in more than $75 \%$ of epithelial cells) $[20,28]$. The anti-p16 ${ }^{\mathrm{INK} 4 \mathrm{a}}$ antibody is normally expressed on nuclei and some cytoplasmic staining. For an abnormal p16 protein expression, there are two patterns, similar to p53 expression: absent or overexpressed ("block" expression) [29]. WT1 expression was considered positive if a nuclear and/or cytoplasmic intense brown staining was identified in more than $75 \%$ of the epithelial cells [20].

CD34 immunostaining was considered positive if a distinctive brown color was present in the membrane of the endothelial cells. The angiogenesis process was further manually analyzed by mean MVD (MVD $\left.{ }_{\text {mean }}\right)$, which was calculated as mean vessels $/ \mathrm{mm}^{2}\left(\times 400\right.$; field size $0.5 \mathrm{~mm}^{2}$; Nikon E200 microscope) [30]. The counting was done under high-power field (HPF) by evaluating three "hot spot" areas (areas with more density of vessels first detected by scrolling the entire section with a low-power view). We included both cluster of marked endothelial cells with a lumen (blood vessels) and single cells with a positive reaction for CD34 [30].

\section{Results}

\section{Clinical and pathological features}

The screening process resulted in 70 patients with OC (eight stage I and 62 stages II-IV), 61 patients with EMs (40 patients - stage I, 13 patients - stage II and eight patients - stage III) and four patients with concomitant ovarian EMs and OC. In the present study, we focused our research on the four patients identified with both ovarian EMs and epithelial OC: endometrioid type two cases (Figure 1) and serous OC type, high-grade
(HGSOC) - two cases (Figure 2). All four cases had stage I EMs.

In terms of age, three patients were in the fertile period, in the proliferative phase and one patient was during menopause. The two patients with endometrioid OCs and EMs had ages between 30-40 years. In the group with serous OC, one patient was between $40-50$ years old and the other between 50-60 years old. None of the patients received treatment for EMs before the diagnosis of EMs and OC. One of the patients was treated for infertility.

All patients were admitted to the hospital for pelvic pain and they were all from a rural environment. The patients with endometrioid carcinomas were diagnosed with earlier stages of cancer (stage I) than those with serous carcinomas, who were with more advanced stages (one stage II and one stage III). None of the patients expressed a difference in EMs $A S F S$ stage. Morphologically, no atypical cytological or architectural EMs features were identified in endometriotic foci. Based on Van Gorp et al. (2004) classification regarding the association of OC and presence of endometriotic foci, we could include one case in category A, one case in category B and the last two in category $\mathrm{C}[10,30]$.

\section{IHC assessment}

Assessment of hormonal receptors (ER, PR) was performed in both glandular and stromal compartment of endometriotic foci and OC. The highest value for $H$-score obtained in EMs cases associated with endometrioid OC was ER - 55 in the epithelial glandular cells and 90 in stromal cells; PR - 45 in the epithelial glandular cells and 25 for stromal cells. The maximum value for $H$-score observed in EMs cases associated with HGSOC was ER -220 in the epithelial glandular cells and 182 in stromal cells; PR - 60 in the epithelial glandular cells and 40 for stromal cells. The maximum value of $H$-score recorded in the endometrioid OC: ER - 190 in the malignant epithelial cells and 50 in the stromal cells; PR - 225 in the malignant epithelial cells and 30 in the stromal cells. In HGSOC, we noticed high values for ER, up to 255 in the malignant epithelial cells and 85 in the stromal cells; PR expression was positive, up to 75 value for $H$-score of the epithelial tumor cells and negative in the stromal cells.

Assessment of Ki67 index of the epithelial component revealed a strong immunoreaction for both types of EAOCs, up to $75 \%$ for endometrioid OC cases and up to $90 \%$ for HGSOC cases. A negative result was observed for the stromal cells of OCs. In the glandular component of endometriotic foci, a low or very low Ki67 index and a negative index was obtained for the stromal component of all of the endometriotic foci.

An altered IHC p53 expression was observed only in HGSOCs ("overexpression type") and non-altered p53 expression ("wild type" pattern) was identified in endometrioid OC and in endometriotic foci. A positive immunostaining for anti-p16 $6^{\mathrm{INK} 4 \mathrm{a}}$ antibody ("block" pattern) and a positive expression for WT1 immunomarker was noticed only in HGSOCs, negative results being observed in endometrioid $\mathrm{OC}$ and endometriotic foci.

Assessment of the angiogenesis through $\mathrm{MVD}_{\text {mean }}$ revealed higher values in OC (up to $125 / \mathrm{mm}^{2}$ for HGSOC and up to $110 / \mathrm{mm}^{2}$ for endometrioid OC) than those 
observed in the endometriotic foci (up to $37 / \mathrm{mm}^{2}$ for EMs associated with endometrioid OC and $51 / \mathrm{mm}^{2}$ for EMs associated with HGSOC).

\section{Discussions}

We do not have enough data to comment on patients' age, previous treatment, symptoms or geographical origin. However, we could exclude uterine-originated pain or contractions [31-33], other ovarian pathologies [34, 35], ovarian surgery [36], infertility or infertility-related painful side effects $[37,38]$. Nor were any of these related to the purpose of the study.

EMs is a benign, chronic inflammatory, sex hormoneinfluenced disease, which can cause pain, infertility and even progression towards malignancy [7, 39, 40]. Despite numerous studies on EMs, its pathogenesis still has unclarities and the transition or association with cancer is not yet completely understood [8].

In the present study, we focused our research on four cases of EMs associated with OC (two with endometrioid
OC and two with serous OC). The morphological diagnosis of EMs was proved by their positivity to CD10 immunomarker in the stromal cells of EMs [14]. Patients with EMs and endometrioid OC were younger and they were diagnosed in earlier stages of cancer, meanwhile the ones with EMs and serous OC were older and they were diagnosed in more advanced stages.

In our cases, most of EAOCs were unilateral, in concordance with other reports, which also emphasized the frequency of unilaterality for EAOC [14]. OCs without EMs are usually bilateral and they are associated with ascites [14]. On the other hand, the frequency of EAOCs could be underestimated because endometriotic foci might be destroyed by malignant cells proliferation or it can remain only a minor residual component. It is difficult or even impossible to detect it, especially for those advanced stages of OCs [11]. With the previously mentioned limitation due to the number of cases, we could not observe a more frequent association of EMs with endometrioid OC, as described by other authors [41].
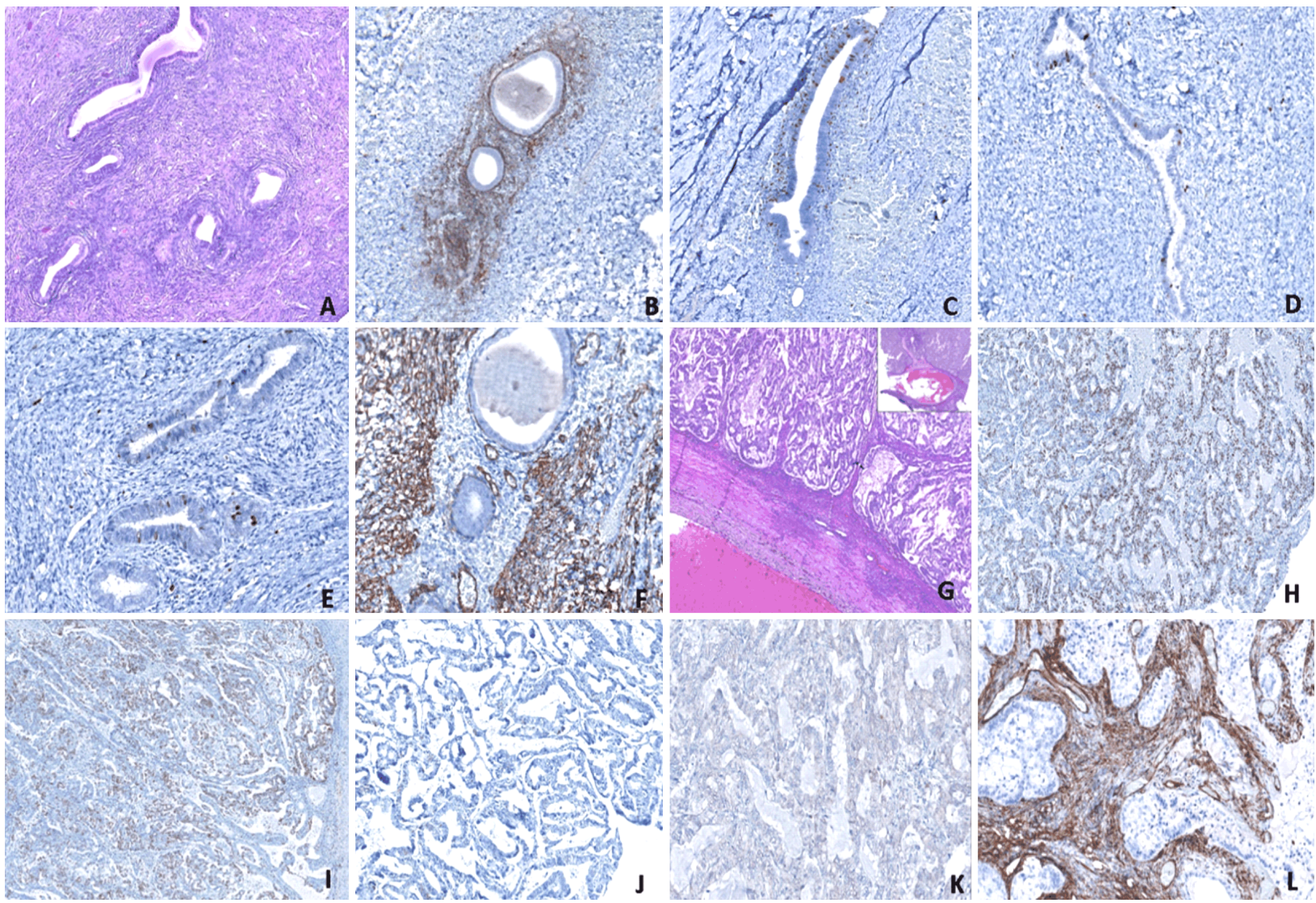

Figure 1 - Morphological and immunohistochemical features of EMs associated with endometrioid OC: (A) Morphological features of endometriotic focus (HE staining, $\times 40) ;(B) A$ CD10-positive immunostaining for the stromal cells of EMs (IHC, ×40); (C) Focally positive nuclear immunostaining for ER in both epithelial and stromal compartment of EMs (IHC, ×100); (D) Focally positive nuclear immunostaining for PR in both epithelial and stromal compartment of EMs (IHC, ×100); (E) Focally positive immunostaining for Ki67 in epithelial and stromal compartment of EMs (IHC, $\times 100)$; (F) Positive immunostaining for CD34 highlighting the vessels in endometriotic focus (IHC, $\times 40)$; (G) Morphological features of endometrioid OC with adjacent endometrioma (HE staining, $\times 40$; inset - scanned image); (H) Intense and diffusely positive nuclear immunostaining for PR in endometrioid OC (IHC, $\times 40)$; (I) Intense and diffusely positive nuclear immunostaining for Ki67 in endometrioid OC (IHC, $\times 40)$; (J) Normal immunoreaction ("wild type") of antip53 antibody in the endometrioid OC (IHC, $\times 100)$; (K) Normal immunostaining for p16 ${ }^{I N K 4 a}$ (weak and focally positive membranous and cytoplasmic immunostaining of the epithelial cells) in the endometrioid OC (IHC, $\times 100)$; (L) Positive immunostaining for anti-CD34 antibody highlighting the vessels in the stroma of endometrioid OC (IHC, $\times 40)$. CD: Cluster of differentiation; EMs: Endometriosis; ER: Estrogen receptor; HE: Hematoxylin-Eosin; IHC: Immunohistochemistry; OC: Ovarian carcinoma; PR: Progesterone receptor. 

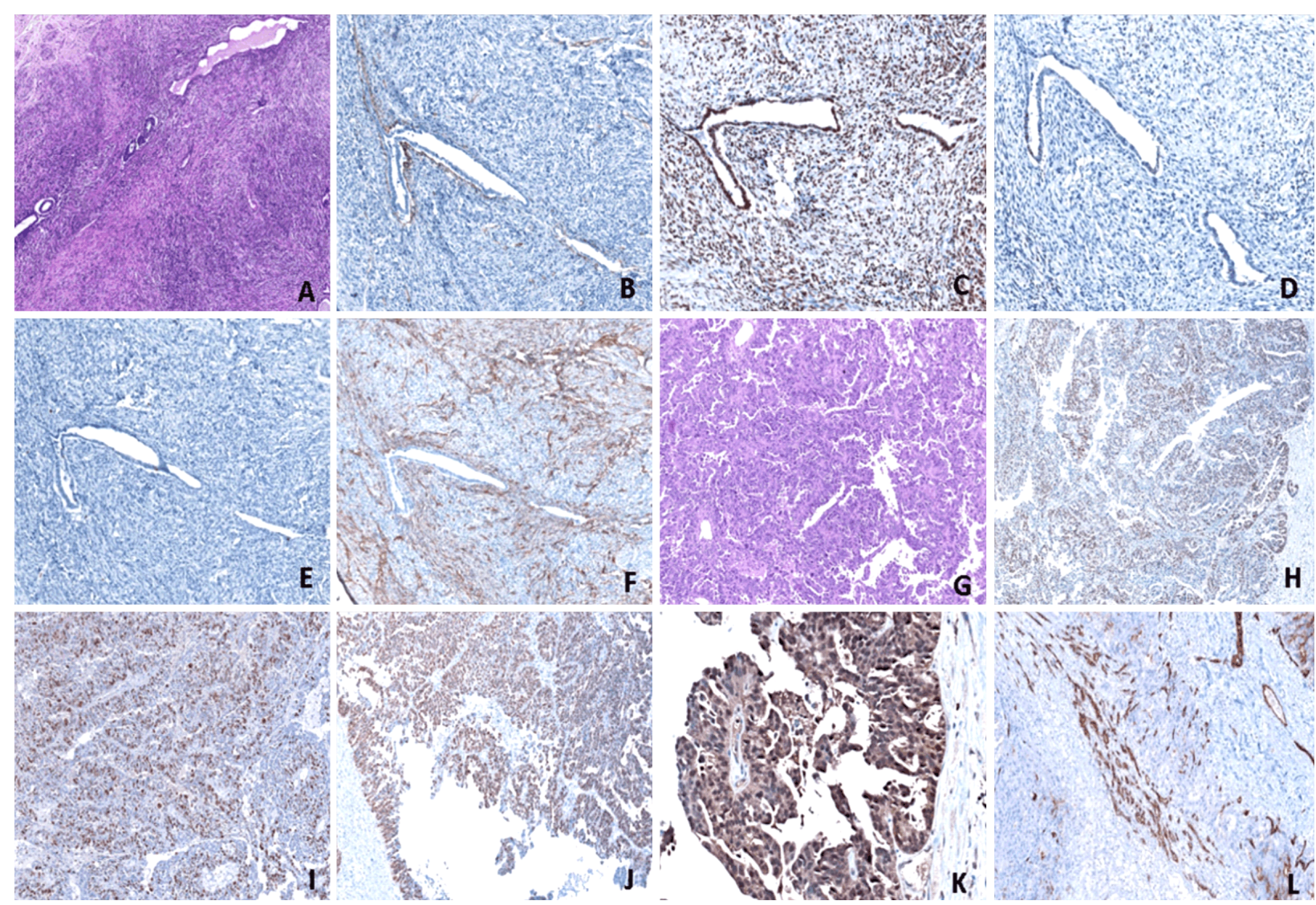

H
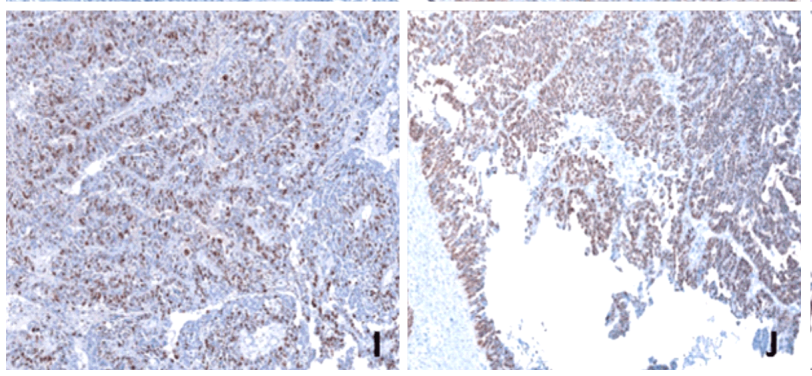

Figure 2 - Morphological and immunohistochemical features of a high-grade serous papillary OC and EMs on the contralateral ovary: (A) Morphological features of endometriotic focus (HE staining, $\times 40)$; (B) CD10 immunostaining of the stromal cells in endometriotic focus (IHC, $\times 40)$; (C) Intense and diffusely positive nuclear immunostaining for $E R$ in both epithelial and stromal compartment of EMs (IHC, $\times 100)$; (D) Moderate and focally positive nuclear immunostaining for PR in both epithelial and stromal compartment of endometriotic focus (IHC, $\times 100)$; (E) Negative immunostaining for Ki67 in both epithelial and stromal compartment of endometriotic focus (IHC, $\times 100)$; (F) Positive immunostaining for CD34 highlighting the microvessels inside the stroma of endometriotic focus (IHC, $\times 40)$; (G) Morphological features of HGSOC (HE staining, $\times 40)$; (H) Intense and diffusely positive nuclear immunostaining for ER in HGSOC (IHC, $\times 100)$; (I) Intense and diffusely positive nuclear immunostaining for anti-Ki67 antibody in HGSOC (IHC, $\times 100)$; (J) Altered p53 expression with "overexpression type" immunostaining of the malignant epithelial cells in HGSOC (IHC, ×100); (K) Intense and diffusely positive membranous and cytoplasmic immunostaining for anti-p16 ${ }^{I N K 4 a}$ antibody ("block expression") in HGSOC (IHC, $\times 200)$; (L) Positive immunoreaction for anti-CD34 antibody highlighting the microvessels inside the stroma of HGSOC (IHC, $\times 40)$. CD: Cluster of differentiation; EMs: Endometriosis; ER: Estrogen receptor; HE: Hematoxylin-Eosin; HGSOC: High-grade serous ovarian carcinoma; IHC: Immunohistochemistry; OC: Ovarian carcinoma; PR: Progesterone receptor.

Hormone receptors are very important in the pathogenesis of both EMs and OCs. The research of Aghajanova et al. (2010) proved that PR functionality is impaired in EMs with persistence of proliferative state [42]. In all our cases, we also observed that the levels of ER expression in the EMs were slightly higher than PR expression for both compartments of EMs, in concordance with reported data [42]. We noticed that the levels of ER expression in OCs were higher than those observed in endometriotic foci. This proves the important role which ER plays in carcinogenesis. In addition, we recorded higher levels of ER expression, for both components, in EMs associated with HGSOC than the ones in EMs associated with endometrioid OC. This result may imply a specific role for ER in the carcinogenesis process for HGSOC associated with EMs. We could not conclude whether it was statistically significant, due to the low number of patients included in our study. Further researches are required to demonstrate its role. Comparing the levels of hormonal receptors expression in the OCs, we noticed high levels of
ER expression in the malignant epithelial cells for both types of OCs, superior to those observed in EMs epithelial cells - as it was previously reported [6].

PR expressed high levels only in endometrioid OCs (mostly in the epithelial cells) and not in HGSOC. Even if there are studies which report that ER were positive in up to $91 \%$ of endometrioid OC and negative for serous OC [43], our results agree with recent reports which noted higher levels of ER also in HGSOC and lower levels for PR [21, 43]. In addition, the present study is in concordance with the research of Sieh et al. (2013), which affirmed that the proportion of OCs that stained positive for PR was the highest in endometrioid OC (67\%) and LGSC $(58 \%)$, intermediate in cases with high-grade serous carcinoma (31\%), and lowest in patients with mucinous carcinoma (17\%) and clear-cell carcinoma (8\%) [44].

Evaluation of hormonal receptors' expression in OCs is important because it was proved that positive expression of PR and/or ER is related with an improved overall survival for endometrioid OC [36]. They influence not 
only the epithelial cells but also the stromal cells and their local metabolism must be well understood. Therefore, their expression must be further analyzed.

The Ki67 immunomarker reflects the cell proliferation and dissemination activity. When its expression is increased, cells become independent and can influence the surrounding tissues. This explains the modified anatomy with important adhesions in advanced stages of EMs [45]. According to some authors, Ki67 expression is directly related with the severity (stage) of EMs [27, 46], but not all the studies reached the same conclusion [45]. There are researchers who suggest that Ki67 expression is also correlated with the size of the endometriotic cyst, in addition to stage of EMs [47]. In our cases, we did not observe any clinical difference in the severity or size of the EMs throughout the presented cases. Therefore, we could observe no association of the Ki67 expression with the severity or size of the EMs. Our results are in concordance with previous studies, which proved that glandular proliferation index in EMs is higher during the proliferative phase than the stroma Ki67 index [48]. As it was expected, we recorded a high Ki67 labeling index in all EAOC (epithelial cells), both types. This corresponds with the fact that Ki67 index is considered as an aggressiveness prognostic marker [17]. We did not observe significant changes of Ki67 index in EMs associated with endometrioid OC versus EMs associated with HGSOC. There were no differences in terms of neoplasia grade, even if some authors found an important association between EMs and low-grade carcinoma, but not with high-grade carcinomas [49]. This can also be because we report a small number of cases. It can also be due to the unavailability of endometriotic tissue in the more advanced cancer cases - and, as we have reported previously, in this article, most of the screened patients in our study were with an advanced disease.

Last edition of $W H O$ presented molecular studies which were done in the last two decades and that led to a new dualistic classification of epithelial OCs, characterized by different morphological types with specific molecular changes and different prognosis [21]. Types I of OC usually are low-grade tumors with slow progression. They are associated with a good prognosis if they are diagnosed in first stages, and represent almost $10 \%$ of deaths caused by epithelial OC [12]. One of the most important molecular features is the lack of tumor protein 53 (TP53) mutations, having a "wild type" pattern on IHC assessment [21]. The study of Scarfone et al. (2014) proved that EMs-associated endometrioid $\mathrm{OC}$ is different from the endometrioid carcinoma which is not associated with EMs [8]. It was concluded that EMs is associated with a high risk of developing epithelial OC, especially endometrioid and clear-cell OC (CCOC), included in type I of OCs. [8]. Nowadays, EMs is considered to be a precursor lesion of OC included in type I tumors, which also encompasses LGSC, mucinous carcinoma and Brenner tumors [12]. In the present research, we identified two cases with EMs associated with endometrioid carcinoma, according to the hypothesis of EMs as a precursor for OC [10].

Type II of OC usually includes high-grade tumors, mostly HGSOC, frequently diagnosed in advanced stages, with a high proliferative activity and with a poor prognosis
$[12,21]$. The most important molecular alteration consists in mutations of TP53, which produce an aberrant p53 protein, immunohistochemically expressed by either "overexpression", which correspond to missense mutations or "null type" expression, which reflects a nonsense mutation [21]. Its precursor lesion is considered to be serous tubal intraepithelial carcinomas (STICs), identified in 50-60\% of cases with HGSOC [45]. Even if EMs is not considered to be a precursor of the type II OC, still there are few cases with EMs and HGSOC reported in literature [11, $24,50]$. Our study reports another two cases.

In our study, the morphology of EMs associated with EAOC does not show atypia, but there are authors who report, in up to $42 \%$ of EAOC, a transition point through atypical EMs [23]. This was firstly defined by LaGrenade \& Silverberg (1988) as cytological criteria (large and hyperchromatic nuclei, tufting, pluristratification, eosinophilic cytoplasm) and/or architectural criteria (glandular hyperplasia and complex structural glands) [51]. Overexpression of p53 is frequently encountered in atypical EMs and p53 immunomarker was proposed to be used to identify those cases with premalignant potential [52]. Akahane et al. (2007) observed p53 mutations only in four cases out of 13 with EMs and CCOC and no p53 mutations in patients with solitary EMs or EMs associated with endometrioid cancer [53]. They concluded that there are genetic alterations which can induce p53 mutations in EMs and transform it in CCOC [53]. On the other hand, the study of Sang et al. (2019) suggested that the expression rate of p53 in EMs is reduced comparing with its expression in the normal endometrium, in which the greatest expression is observed during the secretory phase [19]. These results suggest that apoptosis is reduced in EMs and plays a synergic role together with other factors in its pathogenesis [19]. In the present study, IHC assessment of anti-p53 antibody did not identified mutations in both endometriotic foci and in endometrioid OCs cases. Only HGSOC presented an aberrant p53 protein, in concordance with data from literature [12].

Cell cycle is also negatively influenced by p16 tumor suppressor protein, which is encoded by CDK inhibitor 2A $(C D K N 2 A)$, located on chromosome 9p21.3 [54]. Its role is to slow down the progression of cell cycle from G1 phase to S phase [19]. A "block" expression for p16 represents the hallmark for human papillomavirus (HPV)associated uterine cervical neoplasm. Usually, $\mathrm{p} 16^{\mathrm{INK} 4 \mathrm{a}}$ immunomarker is used to identify HPV-related neoplasm [55]. OCs is not related to HPV infections but different alterations of G1/S phase are frequent [54]. Its "block" expression is identified in $60 \%$ to $80 \%$ of HGSOCs [ 18 , $21]$ and, in conjunction with p53 expression, it can be used to differentiate it from LGSOCs and other OCs included in type I category, as in the last ones there are lower rates of expression $(0-14 \%)[18,21]$. We also obtained an aberrant p16 protein expression in our HGSOC cases, in concordance with the literature $[18,21]$. Even if in the present study, we observed a normal p16 protein expression in endometriotic foci, Sang et al. (2019) reported, on 30 cases of ovarian EMs, that p16 protein expression plays an important role in the pathogenesis of EMs and it is positively correlated with p53 expression [19]. They recorded lower rate of expression for p16 in 
EMs comparative with normal endometrium $(10 \%$ versus $31.03 \%$ ) [19].

WT1 is the most sensitive and specific immunomarker for serous type tumors and it is frequently used in differential diagnosis of serous OCs $(100 \%$ positive for LGSOCs and up to $98 \%$ positive for HGSOCs) and other morphological subtypes (negative expression for CCOC and mucinous OC and $4 \%$ positive for endometrioid OC) $[18,21]$. WT1 expression on endometriotic foci is very rarely reported. From our knowledge, there is only one study who evaluated WT1 expression on EMs associated with endometrioid OC [13] and none on EMs associated with serous OC. In the present research, a WT1-positive expression was obtained in HGSOCs cases but its expression was negative in endometrioid $\mathrm{OC}$ and in endometriotic foci, according to literature $[18,21]$. Its role in predicting a preneoplastic alterations in endometriotic foci depends on its evaluation on a higher number of cases.

Microenvironment of EMs and OCs plays an important role in developing and progression of these lesions. There is an entire constellation of factors involved in pathogenesis of EMs represented by cellular factors (stromal fibroblast, endothelial cells, endometrial epithelial cells and inflammatory cells), steroid hormones or metabolic products like iron [56]. There are different interactions between all of them and, through complex pathways, which are not fully depicted, malignancy appears in some cases. A special attention has been paid to the vascularization of EMs, which include processes like angiogenesis (developing of new blood vessels from pre-existing one), vasculogenesis (de novo developing of blood vessels from circulating endothelial progenitor cells) and inosculation (interconnection of blood vessels) [57]. Angiogenesis is essential in both EMs and in OCs and its quantification can be evaluated by assessing MVD [56, 58]. Ruscito et al. (2018) reported that MVD has a prognostic value in OC and it is a predictor of tumor growth and suggested that anti-angiotherapy can be useful [59]. Similarly to other authors, we noted higher values for MVD in EAOC comparing with EMs and no differences between EMs associated with endometrioid OC, and that associated with HGSOC $[59,60]$. On the other hand, it was proved that there are also higher values between eutopic endometrium associated with EMs in comparing with normal endometrium, mostly in late secretory phase [58]. Considering these facts, anti-angiotherapy can be applied also to treat EMs but supplementary studies and clinical trials are needed.

\section{Conclusions}

Our study could not observe a more frequent association of EMs with endometrioid OC, as described by other authors, but it represents a step forward on the less understood EMs associated with type II of OCs, especially with HGSOC. Cases with EMs associated with HGSOC are extremely rare in the literature - and we have added two more in this group. We did not identify any similarities between EMs and OCs from the morphologically and IHC point of view. As for the differences in-between EMs (depending on their OC association), we recorded higher levels of ER expression, for both epithelial and stromal components, in EMs associated with HGSOC comparing with EMs associated with endometrioid OC. This result may imply a specific role for ER in the carcinogenesis process for HGSOC associated with EMs. Our observations may represent a brick for future researches. If huge breakthroughs have been done in depicting the pathogenesis which links EMs with type I OC, supplementary molecular and proteomics research is necessary to unravel the mechanism(s) of this rare but more aggressive association between EMs and type II OC. Identifying the best marker which can predict the risk of developing OC for the patients with EMs may lead to discover new specific therapeutic agents and therefore a better, tailored therapy.

\section{Conflict of interests}

The authors declare that they have no conflict of interests.

\section{Authors' contributions}

Gabriela-Izabela Bălţătescu, Oana-Sorina Tica and Vlad-Iustin Tica equally contributed to the manuscript.

\section{Acknowledgments}

This work is supported by the project ANTREPRENOR DOC, in the framework of Human Resources Development Operational Programme 2014-2020, financed from the European Social Fund under the contract number 36355/ 23.05.2019 HRD OP/380/6/13 - SMIS code: 123847.

The pathological research was performed in the Center for Research and Development of the Morphological and Genetic Studies of Malignant Pathology from the Ovidius University of Constanţa, POSCCE 2.2.1, Project ID: 1844, SMIS code: 48750, CEDMOG, contract number 627/ 11.03.2014.

\section{References}

[1] Brosens I, Benagiano G. History of endometriosis: a 20thcentury disease. In: Giudice LC, Evers JLH, Healy DL (eds). Endometriosis: science and practice. $1^{\text {st }}$ edition, WileyBlackwell, Singapore, 2012, 3-5.

[2] Izvoranu S, Penciu R, Mocanu ID, Tica V. Chronic pelvic pain of gynecological cause. In: Bratila E, Cirstoiu M (eds). Proceedings of the $14^{\text {th }}$ National Congress of Urogynecology and the National Conference of the Romanian Association for the Study of Pain. Filodiritto Publisher, Bologna, Italy, 2017, 463-465.

[3] Penciu RC, Izvoranu S, Mocanu D, Tica V. Pelvic chronic pain in endometriosis versus adenomyosis. In: Bratila $\mathrm{E}$, Cirstoiu M (eds). Proceedings of the $14^{\text {th }}$ National Congress of Urogynecology and the National Conference of the Romanian Association for the Study of Pain. Filodiritto Publisher, Bologna, Italy, 2017, 566-568.

[4] Penciu RC, Izvoranu S, Mocanu D, Tica V. Correlation between dysmenorrhea and endometriosis: case report. In: Bratila E, Cirstoiu M (eds). Proceedings of the $14^{\text {th }}$ National Congress of Urogynecology and the National Conference of the Romanian Association for the Study of Pain. Filodiritto Publisher, Bologna, Italy, 2017, 569-570.

[5] The American Fertility Society. Revised American Fertility Society classification of endometriosis: 1985. Fertil Steril, 1985, 43(3):351-352. https://doi.org/10.1016/s0015-0282(16)48430-x PMID: 3979573

[6] Bas-Esteve E, Pérez-Arguedas M, Guarda-Muratori GA Acién $M$, Acién $P$. Endometriosis and ovarian cancer: their association and relationship. Eur J Obstet Gynecol Reprod Biol X, 2019, 3:100053. https://doi.org/10.1016/j.eurox.2019. 100053 PMID: 31404281 PMCID: PMC6687431

[7] Heaps JM, Nieberg RK, Berek JS. Malignant neoplasms arising in endometriosis. Obstet Gynecol, 1990, 75(6):1023-1028. PMID: 2188180 
[8] Brilhante AVM, Augusto KL, Portela MC, Sucupira LCG, Oliveira LAF, Pouchaim AJMV, Nóbrega LRM, Magalhães TF, Sobreira LRP. Endometriosis and ovarian cancer: an integrative review (endometriosis and ovarian cancer). Asian Pac J Cancer Prev, 2017, 18(1):11-16. https://doi.org/10.22034/AP JCP.2017.18.1.11 PMID: 28240000 PMCID: PMC5563086

[9] Sevilla IN, Linde FM, Sánchez MPM, Arense JJ, Torroba A Díaz AN, Ferrer MLS. Prognostic importance of atypical endometriosis with architectural hyperplasia versus cytologic atypia in endometriosis-associated ovarian cancer. J Gynecol Oncol, 2019, 30(4):e63. https://doi.org/10.3802/jgo.2019.30.e63 PMID: 31074246 PMCID: PMC6543102

[10] Van Gorp T, Amant F, Neven P, Vergote I, Moerman P. Endometriosis and the development of malignant tumours of the pelvis. A review of literature. Best Pract Res Clin Obstet Gynaecol, 2004, 18(2):349-371. https://doi.org/10.1016/j.bpo bgyn.2003.03.001 PMID: 15157647

[11] Bounous VE, Ferrero A, Fuso L, Ravarino N, Ceccaroni M, Menato G, Biglia N. Endometriosis-associated ovarian cancer: a distinct clinical entity? Anticancer Res, 2016, 36(7):34453449. https://doi.org/ PMID: 27354606

[12] Kurman RJ, Shih IM. The dualistic model of ovarian carcinogenesis: revisited, revised, and expanded. Am J Pathol, 2016 186(4):733-747. https://doi.org/10.1016/j.ajpath.2015.11.011 PMID: 27012190 PMCID: PMC5808151

[13] Stewart CJR, Brennan BA, Chan T, Netreba J. WT1 expression in endometrioid ovarian carcinoma with and without associated endometriosis. Pathology, 2008, 40(6):592-599. https://doi. org/10.1080/00313020802320697 PMID: 18752126

[14] Sumathi VP, McCluggage WG. CD10 is useful in demonstrating endometrial stroma at ectopic sites and in confirming a diagnosis of endometriosis. J Clin Pathol, 2002, 55(5):391392. https://doi.org/10.1136/jcp.55.5.391 PMID: 11986349 PMCID: PMC1769659

[15] Brandenberger AW, Lebovic DI, Tee MK, Ryan IP, Tseng JF, Jaffe RB, Taylor RN. Oestrogen receptor (ER)-alpha and ER-beta isoforms in normal endometrial and endometriosisderived stromal cells. Mol Hum Reprod, 1999, 5(7):651-655. https://doi.org/10.1093/molehr/5.7.651 PMID: 10381820

[16] Păvăleanu I, Amalinei C, Giuşcă SE, Lozneanu L, Avădănei R, Căruntu ID, Balan R. Immunohistochemical profile of endometriosis-associated ovarian carcinoma. Res Clin Med, 2018, 2(2):5-13

[17] Aune G, Stunes AK, Tingulstad S, Salvesen O, Syversen U, Torp SH. The proliferation markers Ki-67/MIB-1, phosphohistone $\mathrm{H}_{3}$, and survivin may contribute in the identification of aggressive ovarian carcinomas. Int J Clin Exp Pathol, 2011, 4(5):444-453. PMID: 21738816 PMCID: PMC3127066

[18] Sallum LF, Andrade L, Ramalho S, Ferracini AC, Natal RA, Brito ABC, Sarian LO, Derchain S. WT1, p53 and p16 expression in the diagnosis of low- and high-grade serous ovarian carcinomas and their relation to prognosis. Oncotarget, 2018, 9(22):15818-15827. https://doi.org/10.18632/oncotarget. 24530 PMID: 29662608 PMCID: PMC5882299

[19] Sang L, Fang QJ, Zhao XB. A research on the protein expression of p53, p16, and MDM2 in endometriosis. Medicine (Baltimore), 2019, 98(14):e14776. https://doi.org/10.1097/MD.00000000 00014776 PMID: 30946310 PMCID: PMC6456087

[20] Carter JH, Deddens JA, Mueller G, Lewis TG, Dooley MK, Robillard MC, Frydl M, Duvall L, Pemberton JO, Douglass LE. Transcription factors WT1 and p53 combined: a prognostic biomarker in ovarian cancer. Br J Cancer, 2018, 119(4):462-470. https://doi.org/10.1038/s41416-018-0191-x PMID: 30057405 PMCID: PMC6134086

[21] Kurman RJ, Carcangiu ML, Herrington CS, Young RH (eds). World Health Organization (WHO) Classification of tumours of female reproductive organs. $4^{\text {th }}$ edition, WHO Classification of Tumours, International Agency for research on Cancer (IARC) Press, Lyon, France, 2014.

[22] Muangtan S, Suknikhom W, Sananpanichkul P, Bhamarapravatana K, Suwannarurk K. Epithelial ovarian cancer with endometriosis is not associated with menopausal status: a co-association study at Prapokklao Hospital. Asian Pac $J$ Cancer Prev, 2018, 19(5):1337-1341. https://doi.org/10.220 34/APJCP.2018.19.5.1337 PMID: 29802696 PMCID: PMC 6031840

[23] Sarmadi S, Izadi-Mood N, Hajeer P, Motevalli D, Masoomian M. The association between endometriosis and surface epithelial ovarian tumors: a review of pathological data. Int J Cancer Manag, 2018, 11(3):e9610. https://doi.org/10.5812/ijcm.9610

[24] Matalliotakis M, Matalliotaki C, Goulielmos GN, Patelarou E, Tzardi M, Spandidos DA, Arici A, Matalliotakis I. Association between ovarian cancer and advanced endometriosis. Oncol Lett, 2018, 15(5):7689-7692. https://doi.org/10.3892/ol.2018. 8287 PMID: 29725467 PMCID: PMC5920362

[25] Mutch DG, Prat J. 2014 FIGO staging for ovarian, Fallopian tube and peritoneal cancer. Gynecol Oncol, 2014, 133(3): 401-414. https://doi.org/10.1016/j.ygyno.2014.04.013 PMID: 24878391

[26] McCarty KS Jr, Miller LS, Cox EB, Konrath J, McCarty KS Sr. Estrogen receptor analyses. Correlation of biochemical and immunohistochemical methods using monoclonal antireceptor antibodies. Arch Pathol Lab Med, 1985, 109(8):716-721. PMID: 3893381

[27] Kahyaoglu I, Kahyaoglu S, Moraloglu O, Zergeroglu S, Sut N, Batioglu S. Comparison of Ki-67 proliferative index between eutopic and ectopic endometrium: a case control study. Taiwan J Obstet Gynecol, 2012, 51(3):393-396. https://doi.org/10. 1016/j.tjog.2012.07.013 PMID: 23040923

[28] Darb-Esfahani S, Denkert C, Stenzinger A, Salat C, Sinn B, Schem C, Endris V, Klare P, Schmitt W, Blohmer JU, Weichert W, Möbs M, Tesch H, Kümmel S, Sinn P, Jackisch C, Dietel M, Reimer T, Loi S, Untch M, von Minckwitz G, Nekljudova V, Loibl S. Role of TP53 mutations in triple negative and HER2positive breast cancer treated with neoadjuvant anthracycline/ taxane-based chemotherapy. Oncotarget, 2016, 7(42):6768667698. https://doi.org/10.18632/oncotarget.11891 PMID: 27611952 PMCID: PMC5356512

[29] Clinton LK, Miyazaki K, Ayabe A, Davis J, Tauchi-Nishi P, Shimizu D. The LAST Guidelines in clinical practice: implementing recommendations for $\mathrm{p} 16$ use. Am J Clin Pathol, 2015, 144(6):844-849. https://doi.org/10.1309/AJCPUXLP7 XD8OQYY PMID: 26572990

[30] Haldorsen IS, Stefansson I, Grüner R, Husby JA, Magnussen IJ, Werner HMJ, Salvesen ØO, Bjørge L, Trovik J, Taxt T, Akslen LA, Salvesen HB. Increased microvascular proliferation is negatively correlated to tumour blood flow and is associated with unfavourable outcome in endometrial carcinomas. Br J Cancer, 2014, 110(1):107-114. https://doi.org/ 10.1038/bjc.2013.694 PMID: 24178757 PMCID: PMC3887294

[31] Tica VI, Cojocaru V, Tica OS, Berceanu S, Tica AA. Cyclic ADP-ribose $/ \mathrm{Ca}^{2+}$ system in uterine smooth muscle cells. Gineco.ro, 2011, 7(2):193-194.

[32] Tica AA, Dun E, Tica V, Cojocaru V, Tica OS, Berceanu S. The autonomic innervation of the uterus. A short review on pharmacological aspects. Gineco.ro, 2011, 7(2):86-91.

[33] Tica AA, Tica VI, Tica OS, Dun E, Berceanu S, Tica I. Endothelin I activates the NAADP signaling complex on myometrial smooth muscle cell. Gineco.ro, 2010, 6(4):254-260.

[34] Tica I, Tica OS, Nicoară AD, Tica VI, Tica AA. Ovarian teratomas in a patient with Bardet-Biedl syndrome, a rare association. Rom J Morphol Embryol, 2016, 57(4):1403-1408. PMID: 28174811

[35] Tica V. Primary ovarian pregnancies. Gineco.ro, 2011, 7(4): $179-180$.

[36] Tica V. Laparoscopic ovarian drilling. Gineco.ro, 2011, 7(3): 119-120.

[37] Tica V. La Fertilité. Contraception Fertilité Sexualité, 1996, 24(3):173-183.

[38] Tica V, Hedon B, Eid J, Audibert F, Benos P, Boulot P, Laffargue F, Viala JL. Determination of adverse reactions to the stimulation of ovulation in vitro fertilization [Effets secondaires de la stimulation ovarienne dans le cadre de la fécondation in vitro]. Contraception Fertilité Sexualité, 1991, 19(7-8):580-582.

[39] Penciu RC, Steriu L, Izvoranu S, Postolache I, Tica AA, Mocanu D, Tica OS, Sarbu V, Deacu M, Baltatescu G, Tica I, Petcu L, Tica VI. CD10, CD34 and Ki67 immunohistochemical markers expression in endometriosis and adenomyosis. Rev Chim (Bucharest), 2019, 70(4):1323-1327. https://doi.org/10. 37358/RC.19.4.7119

[40] Cozaru GC, Aschie M, Mitroi A, Brinzan C. P01.87C: The risk of spontaneous abortion in subfertile couples. Abstracts from the $52^{\text {nd }}$ European Society of Human Genetics (ESHG) Conference: Posters, Eur J Hum Genet, 2019, 27(11 Suppl 2): 1211. https://doi.org/10.1038/s41431-019-0494-2 
[41] Kim HS, Kim TH, Chung HH, Song YS. Risk and prognosis of ovarian cancer in women with endometriosis: a metaanalysis. Br J Cancer, 2014, 110(7):1878-1890. https://doi.org/ 10.1038/bjc.2014.29 PMID: 24518590 PMCID: PMC3974076

[42] Aghajanova L, Velarde MC, Giudice LC. Altered gene expression profiling in endometrium: evidence for progesterone resistance. Semin Reprod Med, 2010, 28(1):51-58. https://doi.org/10. 1055/s-0029-1242994 PMID: 20104428

[43] Lai CR, Hsu CY, Chen YJ, Yen MS, Chao KC, Li AFY. Ovarian cancers arising from endometriosis: a microenvironmental biomarker study including ER, HNF1 $\beta$, p53, PTEN, BAF250a and COX-2. J Chin Med Assoc, 2013, 76(11):629-634. https:// doi.org/10.1016/j.jcma.2013.07.008 PMID: 23962610

[44] Sieh W, Köbel M, Longacre TA, Bowtell DD, deFazio A, Goodman MT, Høgdall E, Deen S, Wentzensen N, Moysich KB, Brenton JD, Clarke BA, Menon U, Gilks CB, Kim A, Madore J, Fereday S, George J, Galletta L, Lurie G, Wilkens LR, Camey ME, Thompson PJ, Matsuno RK, Krüger Kjær S, Jensen A Høgdall C, Kalli KR, Fridley BL, Keeney GL, Vierkant RA, Cunningham JM, Brinton LA, Yang HP, Sherman ME, GarcíaClosas M, Lissowska J, Odunsi K, Morrison C, Lele S, Bshara W, Sucheston L, Jimenez-Linan M, Driver K, Alsop J, Mack M, McGuire V, Rothstein JH, Rosen BP, Bernardini MQ, Mackay H Oza A, Wozniak EL, Benjamin E, Gentry-Maharaj A, Gayther SA Tinker AV, Prentice LM, Chow C, Anglesio MS, Johnatty SE, Chenevix-Trench G, Whittemore AS, Pharoah PDP, Goode EL, Huntsman DG, Ramus SJ. Hormone-receptor expression and ovarian cancer survival: an Ovarian Tumor Tissue Analysis Consortium study. Lancet Oncol, 2013, 14(9):853-862. https:// doi.org/10.1016/S1470-2045(13)70253-5 PMID: 23845225 PMCID: PMC4006367

[45] Brătilă E, Brătilă $C P$, Comandaşu DE, Bauşic V, Vlădescu CT, Mehedinţu C, Berceanu C, Cîrstoiu MM, Mitroi G, Stănculescu R. The assessment of immunohistochemical profile of endometriosis implants, a practical method to appreciate the aggressiveness and recurrence risk of endometriosis. Rom $J$ Morphol Embryol, 2015, 56(4):1301-1307. PMID: 26743275

[46] Li SF, Nakayama K, Masuzawa H, Fujii S. The number of proliferating cell nuclear antigen positive cells in endometriotic lesions differs from that in the endometrium. Analysis of PCNA positive cells during the menstrual cycle and in post-menopause. Virchows Arch A Pathol Anat Histopathol, 1993, 423(4):257263. https://doi.org/10.1007/BF01606888 PMID: 7901938

[47] Alif M, Anwar R, Pribadi A. Ki-67 expression is correlated with cyst size and stage of endometriosis. Indones J Obstet Gynecol, 2013, 1(3):124-128. https://doi.org/10.32771/inajog. v1i3.350

[48] Nisolle M, Casanas-Roux F, Donnez J. Immunohistochemica analysis of proliferative activity and steroid receptor expression in peritoneal and ovarian endometriosis. Fertil Steril, 1997 68(5):912-919. https://doi.org/10.1016/s0015-0282(97)00341-5 PMID: 9389825

[49] Pearce CL, Templeman C, Rossing MA, Lee A, Near AM, Webb PM, Nagle CM, Doherty JA, Cushing-Haugen KL, Wicklund KG, Chang-Claude J, Hein R, Lurie G, Wilkens LR, Carney ME, Goodman MT, Moysich K, Kjaer SK, Hogdall E, Jensen A, Goode EL, Fridley BL, Larson MC, Schildkraut JM, Palmieri RT, Cramer DW, Terry KL, Vitonis AF, Titus LJ, Ziogas A, Brewster W, Anton-Culver H, Gentry-Maharaj A, Ramus SJ, Anderson AR, Brueggmann D, Fasching PA, Gayther SA, Huntsman DG, Menon U, Ness RB, Pike MC Risch $\mathrm{H}$, Wu $\mathrm{AH}$, Berchuck A; Ovarian Cancer Association Consortium. Association between endometriosis and risk of histological subtypes of ovarian cancer: a pooled analysis of case-control studies. Lancet Oncol, 2012, 13(4):385-394. https:// doi.org/10.1016/S1470-2045(11)70404-1 PMID: 22361336 PMCID: PMC3664011

[50] Aris A. Endometriosis-associated ovarian cancer: a ten-year cohort study of women living in the Estrie Region of Quebec Canada. J Ovarian Res, 2010, 3:2. https://doi.org/10.1186/ 1757-2215-3-2 PMID: 20205767 PMCID: PMC2822768
[51] LaGrenade A, Silverberg SG. Ovarian tumors associated with atypical endometriosis. Hum Pathol, 1988, 19(9):10801084. https://doi.org/10.1016/s0046-8177(88)80090-x PMID: 3417292

[52] Sáinz de la Cuesta R, Izquierdo M, Cañamero M, Granizo JJ, Manzarbeitia F. Increased prevalence of p53 overexpression from typical endometriosis to atypical endometriosis and ovarian cancer associated with endometriosis. Eur J Obstet Gynecol Reprod Biol, 2004, 113(1):87-93. https://doi.org/10. 1016/S0301-2115(03)00367-1 PMID: 15036718

[53] Akahane T, Sekizawa A, Purwosunu Y, Nagatsuka M, Okai T. The role of p53 mutation in the carcinomas arising from endometriosis. Int J Gynecol Pathol, 2007, 26(3):345-351. https://doi.org/10.1097/pgp.0b013e31802b41a8 PMID: 17581423

[54] Rambau PF, Vierkant RA, Intermaggio MP, Kelemen LE, Goodman MT, Herpel E, Pharoah PD, Kommoss S, JimenezLinan M, Karlan BY, Gentry-Maharaj A, Menon U, Hernando Polo S, Dos Reis FJC, Doherty JA, Gayther SA, Sharma R, Larson MC, Harnett PR, Hatfield E, de Andrade JM, Nelson GS, Steed H, Schildkraut JM, Carney ME, Høgdall E, Whittemore AS, Widschwendter M, Kennedy CJ, Wang F, Wang Q, Wang C, Armasu SM, Daley F, Coulson P, Jones ME, Anglesio MS, Chow C, de Fazio A, García-Closas M, Brucker SY, Cybulski C, Harris HR, Hartkopf AD, Huzarski T, Jensen A, Lubiński J, Oszurek O, Benitez J, Mina F, Staebler A, Taran FA, Pasternak J, Talhouk A, Rossing MA, Hendley J; AOCS Group; Edwards RP, Fereday S, Modugno F, Ness RB, Sieh W, El-Bahrawy MA, Winham SJ, Lester J, Kjaer SK, Gronwald J, Sinn P, Fasching PA, Chang-Claude J, Moysich KB, Bowtell DD, Hernandez BY, Luk $H$, Behrens S, Shah M, Jung A, Ghatage P, Alsop J, Alsop K, García-Donas J, Thompson PJ, Swerdlow AJ, Karpinskyj C, Cazorla-Jiménez A, García MJ, Deen S, Wilkens LR, Palacios J, Berchuck A, Koziak JM, Brenton JD, Cook LS, Goode EL, Huntsman DG, Ramus SJ, Köbel M. Association of p16 expression with prognosis varies across ovarian carcinoma histotypes: an Ovarian Tumor Tissue Analysis Consortium study. J Pathol Clin Res, 2018, 4(4):250-261. https://doi.org/10.1002/cjp2.109 PMID: 30062862 PMCID: PMC6174617

[55] Klaes R, Friedrich T, Spitkovsky D, Ridder R, Rudy W, Petry U, Dallenbach-Hellweg G, Schmidt D, von Knebel Doeberitz M. Overexpression of $\mathrm{p} 16^{\mathrm{INK} 4 \mathrm{~A}}$ as a specific marker for dysplastic and neoplastic epithelial cells of the cervix uteri. Int J Cancer, 2001, 92(2):276-284. https://doi.org/10.1002/ijc.1174 PMID: 11291057

[56] Wendel JRH, Wang X, Hawkins SM. The endometriotic tumor microenvironment in ovarian cancer. Cancers (Basel), 2018, 10(8):261. https://doi.org/10.3390/cancers10080261 PMID: 30087267 PMCID: PMC6115869

[57] Laschke MW, Menger MD. Basic mechanisms of vascularization in endometriosis and their clinical implications. Hum Reprod Update, 2018, 24(2):207-224. https://doi.org/10.10 93/humupd/dmy001 PMID: 29377994

[58] Ceyhan ST, Onguru O, Baser I, Gunhan O. Expression of cyclooxygenase-2 and vascular endothelial growth factor in ovarian endometriotic cysts and their relationship with angiogenesis. Fertil Steril, 2008, 90(4):988-993. https://doi.org/10. 1016/j.fertnstert.2007.07.1332 PMID: 18053993

[59] Ruscito I, Castillo-Tong DC, Vergote I, Ignat I, Stanske M, Vanderstichele A, Glajzer J, Kulbe H, Trillsch F, Mustea A, Kreuzinger C, Panici PB, Gourley C, Gabra H, Nuti M, Taube ET, Kessler M, Sehouli J, Darb-Esfahani S, Braicu El. Characterisation of tumour microvessel density during progression of high-grade serous ovarian cancer: clinico-pathological impact (an OCTIPS Consortium study). Br J Cancer, 2018, 119(3): 330-338. https://doi.org/10.1038/s41416-018-0157-z PMID: 29955134 PMCID: PMC6070919

[60] Arjunan A, Balajij GST, Mani R, Sudha B, Narmadha C, Malaichamy V. Expression of p53 and CD34 in surface epithelial tumors of ovary. IOSR J Dent Med Sci, 2016, 15(9): 1-13. https://doi.org/10.9790/0853-1509090113

\section{Corresponding author}

Irina Tica, Associate Professor, MD, PhD, Department of Internal Medicine, Ovidius University of Constanţa, Campus, 1 University Alley, Housing B, 900470 Constanţa, Romania; Phone +40724-834 864, e-mail: irinatica@gmail.com 